\title{
Analysis of the correlation between adiponectin gene polymorphism and metabolic syndrome incidence and its relationship with the degree of atherosclerosis in patients
}

\author{
GUANGYA WANG ${ }^{1,2}$, GUANGYAO SONG ${ }^{1,3}$, LINXIA WANG $^{2}$, FANG GAO $^{2}$, \\ NINGNING GUO $^{2}$, YUNNA ZHANG ${ }^{2}$, NAIRUI ZHAO ${ }^{2}$ and XIUPING YIN ${ }^{1}$ \\ ${ }^{1}$ Teaching and Research Section of Medicine, Hebei Medical University, Shijiazhuang, Hebei 050017; \\ ${ }^{2}$ Second Department of Endocrinology and Metabolism, Cangzhou Central Hospital, Cangzhou, \\ Hebei 061001; ${ }^{3}$ Department of Endocrinology and Metabolism, Hebei Provincial \\ People's Hospital, Shijiazhuang, Hebei 050017, P.R. China
}

Received July 17, 2017; Accepted September 4, 2017

DOI: $10.3892 / \mathrm{etm} .2017 .5149$

\begin{abstract}
The aim of the present study was to determine the correlation between adiponectin (APN) gene polymorphism, metabolic syndrome incidence, and degree of atherosclerosis in patients with this disease. The study was conducted on 369 unrelated patients, diagnosed with metabolic abnormalities. The patients were divided into the metabolic syndrome group (MS group, $n=182)$, the metabolic abnormality group $(n=187)$ and the control group with metabolic normality $(n=134)$, as per the degree of metabolic abnormality. The gene polymorphism of rs121917815 site of APN gene was detected by TaqMAN probe technique, and the OR values of different genotypes and alleles were calculated. The APN protein, $\mathrm{C}$-reactive protein (CRP), IL-1 and high-density lipoprotein (HDL) $2 \mathrm{a}$ and $2 \mathrm{~b}$ expression level changes were detected by immunoblotting. The atherosclerosis index (AI) of each allele in patients with MS was calculated. Compared with the control group, the expression levels of APN protein in the metabolic abnormality and MS groups were significantly decreased. However, there was no distinct difference in the comparison of gene polymorphism between the control and metabolic abnormality groups. The $\mathrm{CC}$ genotype frequency and $\mathrm{C}$ allele frequency of rs121917815 polymorphic site in the MS group were significantly increased, compared with the control group. The TT genotype frequency and $\mathrm{T}$ allele frequency were significantly decreased and the OR values of the $\mathrm{CC}$ genotype and $\mathrm{C}$ allele were increased. The results of immunoblotting showed that there was no obvious change of CRP, IL-1, HDL-2a and HDL-2b in the three groups, and there was no statistically
\end{abstract}

Correspondence to: Dr Guangyao Song, Department of Endocrinology and Metabolism, Hebei Provincial People's Hospital, 348 Heping Road, Shijiazhuang, Hebei 050017, P.R. China E-mail: songguangyao1104@163.com

Key words: adiponectin gene, atherosclerosis, polymorphic site, metabolic syndrome significant difference in the comparison of AI between the MS and control groups as well as the metabolic abnormality group. The APN gene polymorphic site rs121917815 is associated with MS. The occurrence of CC genotype and $\mathrm{C}$ allele increased the incidence of MS, but it did not increase the degree of atherosclerosis in MS patients.

\section{Introduction}

Metabolic syndrome is a pathological state that contains multiple metabolic abnormalities, which is manifested in the form of hyperglycemia, hyperlipoidemia, blood lipid disorder, obesity and other clinical features (1). Blood glucose and blood lipid metabolic disorders also significantly increase the probability of cardiovascular disease in patients (2). Atherosclerosis is the main cause for the induction of multiple cardiovascular diseases, but whether there is a direct correlation between MS and atherosclerosis remains unclear. Many clinical data and studies have found that the central link of metabolic syndrome is insulin resistance (3).

Adiponectin (APN) is located on chromosome $3 q 27$ and contains three exons and two groups of introns. Human APN protein structure has 244 amino acids, while the C-terminal aromatic amino acid globular sequence is the key part of the activity of APN protein (4). As an important upstream factor regulating the activity of insulin, APN has widely drawn attention since its discovery (5). Previous studies have confirmed that $A P N$ gene has important physiological functions and is closely associated with the incidence of cardio-cerebral vascular disease, obesity, and MS (6-8). Completion of genome sequencing plays an important role in the diagnosis and prediction of human diseases. In recent years, an increasing number of APN polymorphic sites have been found in the genome, while many polymorphic sites have an important relationship with the occurrence of multiple diseases (9-11). Previous studies found that $A P N$ gene single nucleotide polymorphism (SNP) rs266729 is closely related to Type 2 diabetes mellitus (T2DM), but whether this site could increase the incidence of MS and the degree of atherosclerosis in patients 
with MS remains unclear. Therefore, APN rs266729 gene polymorphisms in the metabolic syndrome group $(n=182)$, the metabolic abnormality group $(n=187)$ and the control group ( $\mathrm{n}=134)$ were detected, and the levels of plasma in APN protein and atherosclerosis-related protein were examined to analyze the correlation between adiponectin (APN) gene polymorphism and metabolic syndrome and its relationship with the degree of atherosclerosis in the patients included in the present study.

\section{Materials and methods}

Subjects. The study was conducted on 264 subjects, admitted to the Department of Medicine April 2008 and May 2013, and who were diagnosed as obese $(\mathrm{BMI} \geq 28)$. There were 145 male and 119 female cases, with an average age of $54 \pm 0.6$ years Of the 264 subjects, 114 cases were selected as the control group; 71 male and 43 female cases, with an average age of $55 \pm 0.3$ years.

Informed consent was obtained from all the subjects and it was taken into consideration that the subjects were not related to each other. The study was approved by the Ethics Committee of Hebei Medical University.

MS observation index and measurement. The body mass index (BMI), waist circumference and hip circumference were measured to calculate the waist-to-hip ratio. The triglyceride and high-density lipoprotein (HDL) were detected by MINDRAY sublimation automatic analyzer (Mindray, Shenzhen, China). The fasting blood glucose was determined by glucose oxidase assay and the fasting insulin was determined by radioimmunoassay.

Diagnosis and grouping of MS. Diagnosis of MS was based on WHO (1999) T2DM diagnostic criteria, the hyperglycemia criterion which included impaired glucose tolerance, impaired fasting blood glucose and impaired glucose regulation. As per the 1999 WHO/ISII diagnostic criteria, the hypertension criterion was defined as for the multiple blood pressure measurements on the different days, the systolic blood pressure was $\geq 140 \mathrm{mmHg}$ and/or the diastolic blood pressure was $\geq 90 \mathrm{mmHg}$. MS criterion was in accordance with the diagnostic criteria proposed by the Chinese Medical Association in 2004. The subjects were divided into three groups based on the presence and degree of metabolic abnormality. The MS group $(n=142)$ required three items or all of the four items as follows: i) overweight and/or obesity: BMI $\geq 25.0 \mathrm{~kg} / \mathrm{m}^{2}$; ii) hyperglycemia: fasting blood glucose $\geq 6.1 \mathrm{mmol} / 1$ and/or $2 \mathrm{~h} \mathrm{PG} \geq 7.8 \mathrm{mmol} / \mathrm{l}$, and/or the patients who were diagnosed as having diabetes and were receiving treatment; iii) hypertension: blood pressure $\geq 140 / 90 \mathrm{mmHg}$, and/or the patients who diagnosed as hypertension and were receiving treatment; iv) blood lipid disorder: triglyceride $\geq 1.7 \mathrm{mmol} / 1$ and/or HDL-C: male $<0.9 \mathrm{mmol} / 1$ and female $<1.0 \mathrm{mmol} / \mathrm{l}$. The 122 cases in the metabolic abnormality group met one or two of the above MS criteria. The normal control group comprised individuals who met none of the MS criteria.

Sample collection. Venous blood $(5 \mathrm{ml})$ was taken after patients fasted for $12 \mathrm{~h}$. Five milliliters was used to extract the peripheral blood genomic DNA using the routine chloroform method after anticoagulation. One milliliter was used to detect blood glucose, blood lipid and HDL after procoagulation and separating the serum. Then, $4 \mathrm{ml}$ was used to detect the related protein expression level changes in serum by immunoblotting.

Gene polymorphism detection. The rs121917815 gene sequence was ACCTGGAGAAGGTGCCTATGTATAC[C/T]GCTCA GCATTCAGTGTGGGATTGGA. The PCR primer sequence was rs121917815 upstream 5'-AGGTCCCCGAGGCTTTCCG-3' and downstream primer 5'-TAGAAGATCTTGGTAAAGGCG AAT-3'. TaqMAN probe sequence was 5'-ACCTGGAGAAGG TGCCTATGTATACT(C)GCTCAGCATTCAGTG-3', and FAM was marked at the T allele 5'-terminal, VIC was marked at the $\mathrm{C}$ allele 5'-terminal, while TAMRA was marked at 3'-terminal (Shanghai Shengshun Biological Technology Co., Ltd., Shanghai, China). APN rs121917815 gene polymorphism was detected by quantitative PCR. The reaction conditions were activating UNG enzyme at $50^{\circ} \mathrm{C}$ for $2 \mathrm{~min}$, pre-denaturation at $94^{\circ} \mathrm{C}$ for $4 \mathrm{~min}$, denaturation at $94^{\circ} \mathrm{C}$ for $30 \mathrm{sec}$, annealing at $54^{\circ} \mathrm{C}$ for $40 \mathrm{sec}$, extension at $60^{\circ} \mathrm{C}$ for $45 \mathrm{sec}$, a total of 40 cycles, and extension at $72^{\circ} \mathrm{C}$ for $10 \mathrm{~min}$ was the final condition. After each cycle, the fluorescence intensity of the PCR product was detected.

Evaluation of the degree of atherosclerosis. C-reactive protein (CRP), IL-1, HDL-2a and HDL-2b immunoblotting as well as AI were used to evaluate the degree of atherosclerosis in the patients. The atherosclerosis index (AI) was calculated as: [Total cholesterol (TC)-HDL]/HDL. Normal AI was set as $<4$, while AI $>4$ suggests presence of atherosclerosis.

Detecting APN protein, CRP, IL-1, HDL-2 a and HDL-2b expression level changes by immunoblotting. After separating the target protein using $12 \%$ SDS gel, a cross-flow transferring membrane using $350 \mathrm{~mA}$ current was performed for $4 \mathrm{~h}$, and the sample was sealed using $10 \%$ BSA for $1 \mathrm{~h}$. The primary antibody dilution was performed in accordance with the antibody specification. After $4^{\circ} \mathrm{C}$ overnight, the membrane was washed three times with TBST buffer for $20 \mathrm{~min}$. Then, it was diluted in accordance with the secondary antibody specification, at room temperature for $1 \mathrm{~h}$, and the membrane was washed three times with TBST buffer for $20 \mathrm{~min}$. The sample was then treated with ECL, and color development was carried out in the dark. After scanning, the optical density was analyzed by ImageJ, and the data were collected for statistical treatment using SPSS software.

Statistical analysis. SPSS 15.0 software (Chicago, IL, USA) was used for the analysis of collected data. The experimental data were expressed as mean $\pm \mathrm{SD}$, and a t-test was used for analyzing the difference among the groups. The Chi-square test was used for the comparison of countable data among the groups. $\mathrm{P}<0.05$ suggested that the difference was statistically significant.

\section{Results}

Comparison of clinical data and serum APN protein expression changes in the three groups. The clinical data of the 
Table I. Comparison of physical and baseline clinical data between the three study groups.

\begin{tabular}{lccr}
\hline Detection items & Control group & Metabolic abnormality group & MS group \\
\hline BMI $\left(\mathrm{kg} / \mathrm{m}^{2}\right)$ & $21.54 \pm 0.212$ & $4.61 \pm 0.34^{\mathrm{a}}$ & $27.68 \pm 0.15^{\mathrm{a}}$ \\
Waist-to-hip ratio & $0.78 \pm 0.06$ & $0.87 \pm 0.03^{\mathrm{a}}$ & $0.95 \pm 0.04^{\mathrm{b}}$ \\
Abdominal fat area $\left(\mathrm{cm}^{2}\right)$ & $37.64 \pm 4.527$ & $1.26 \pm 3.43^{\mathrm{b}}$ & $109.13 \pm 1.26^{\mathrm{a}}$ \\
Systolic blood pressure $(\mathrm{mmHg})$ & $113.56 \pm 1.2312$ & $4.32 \pm 1.35^{\mathrm{a}}$ & $140.13 \pm 1.52^{\mathrm{b}}$ \\
Diastolic blood pressure $(\mathrm{mmHg})$ & $70.92 \pm 1.017$ & $9.03 \pm 0.92^{\mathrm{a}}$ & $90.42 \pm 0.77^{\mathrm{b}}$ \\
Triglyceride (mmol/l) & $1.10 \pm 0.04$ & $1.52 \pm 0.06^{\mathrm{a}}$ & $2.42 \pm 0.03^{\mathrm{b}}$ \\
HDL (mmol/l) & $1.36 \pm 0.02$ & $1.19 \pm 0.07^{\mathrm{b}}$ & $1.12 \pm 0.06^{\mathrm{a}}$ \\
Fasting blood glucose $(\mathrm{mmol} / \mathrm{l})$ & $4.97 \pm 0.11$ & $5.54 \pm 0.06^{\mathrm{a}}$ & $6.01 \pm 0.73^{\mathrm{a}}$ \\
Fasting insulin (nmol/l) & $0.06 \pm 0.01$ & $0.09 \pm 0.02^{\mathrm{b}}$ & $0.11 \pm 0.01^{\mathrm{b}}$ \\
\hline
\end{tabular}

${ }^{\mathrm{a}} \mathrm{P}<0.05,{ }^{\mathrm{b}} \mathrm{P}<0.01$ compared with the control group; ${ }^{\mathrm{a}}<0.05,{ }^{\mathrm{b}} \mathrm{P}<0.01$ compared with the metabolic abnormality group. $1 \mathrm{mmHg}=0.133 \mathrm{kPa}$.

Table II. rs121917815 genotype and allele frequency.

\begin{tabular}{lccccccc}
\hline & \multicolumn{9}{c}{ Genotype } & & \multicolumn{2}{c}{ Allele } \\
\cline { 2 - 4 } \cline { 7 - 8 } Groups & Cases & TT & CT & CC & & T & C \\
\hline Control group & 114 & $37(32.45 \%)$ & $36(31.58 \%)$ & $41(35.96 \%)$ & & $110(48.24 \%)$ & $118(51.76 \%)$ \\
Metabolic abnormality group & 122 & $42(34.42 \%)$ & $37(30.32 \%)$ & $43(35.24 \%)$ & & $120(49.59 \%)$ & $123(50.41 \%)$ \\
MS group & 142 & $32(22.53 \%)$ & $42(29.58 \%)$ & $68(47.89 \%)$ & & $106(37.32 \%)$ & $178(62.68 \%)$ \\
$\chi^{2}$ & & & 26.52 & & & 34.73 \\
P-value & & & $<0.001$ & & & $<0.001$ \\
\hline
\end{tabular}
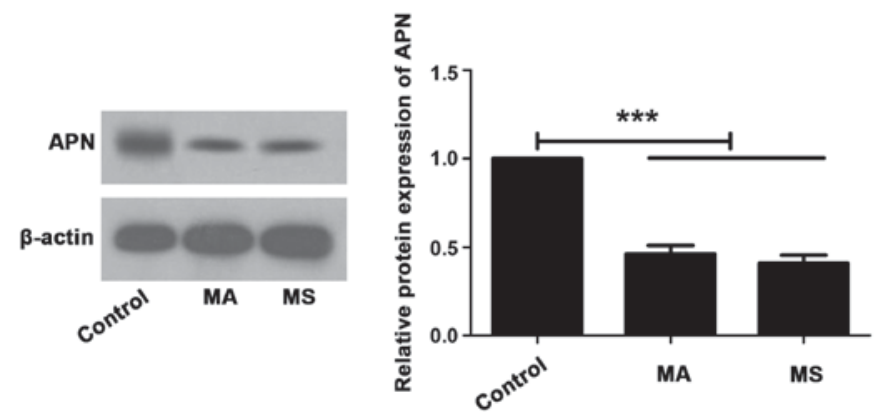

Figure 1. Serum APN protein expression levels in the control group, the metabolic abnormality (MA) group and the MS group.

control, the metabolic abnormality and the MS group showed that the body mass index, waist-to-hip ratio, abdominal fat area, systolic blood pressure, diastolic blood pressure, and fasting insulin levels in the MS group were higher than those in the control group and the metabolic abnormality group $(\mathrm{P}<0.05)$, while the index levels in the metabolic abnormality group were higher than those in the control group $(\mathrm{P}<0.05)$. The serum APN and HDL levels of the MS group were lower than those of the metabolic abnormality group. The HDL level in the metabolic abnormality group was lower than that in the control group $(\mathrm{P}<0.05)$, but there was no statistical significance in the difference of serum APN between the two groups $(\mathrm{P}>0.05)$ (Table I). Compared with the control group, serum

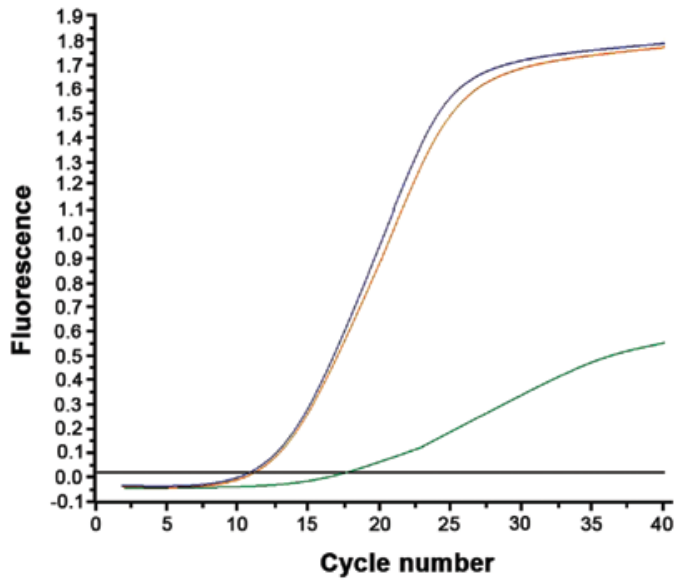

Figure 2. Detecting gene polymorphic sites by quantitative PCR. The blue line was $\mathrm{T}$ genotype fluorescence intensity, the red line is $\mathrm{C}$ genotype fluorescence intensity, and the green line is the blank sample fluorescence intensity.

APN protein expression levels in the metabolic abnormality group and the MS group were decreased (Fig. 1).

Gene rs 121917815 polymorphic site detection and allele frequency. TaqMAN probe was inserted into the PCR product containing the mutation sequence to detect the product containing different alleles using different fluorescence, and to determine the APN polymorphic site in the individual. The results are shown in Fig. 2. 
Table III. Distribution of rs121917815 genotypes and alleles in patients with MS.

\begin{tabular}{lcccccccc}
\hline & \multicolumn{3}{c}{ Genotypes } & & & \multicolumn{2}{c}{ Alleles } \\
\cline { 2 - 3 } Groups & Cases & TT & TC & CC & & T & C \\
\hline Control group & 114 & 37 & 36 & 41 & & 110 & 118 \\
Metabolic abnormality group & 122 & 42 & 37 & 43 & & 120 & 123 \\
MS group & 142 & 32 & 42 & 68 & & 106 & 178 \\
\hline
\end{tabular}

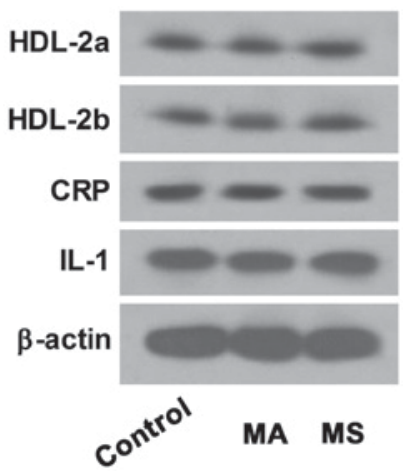

Figure 3. Expression level changes of atherosclerosis-related indexes including CRP, IL-1, HDL-2a and HDL-2b.

The TT, TC and CC genotype frequency and the T and C allele probability were obtained by the statistical analysis of polymorphic site rs121917815 genotype in the control group, the metabolic abnormality group and the MS group (Table II). There was no significant difference in the comparison of the three genotype and allele frequencies between the control and metabolic abnormality groups $(\mathrm{P}>0.05)$. The $\mathrm{CC}$ genotype and $\mathrm{C}$ allele frequencies in the MS group were significantly increased. Compared with the control group, TT genotype and $\mathrm{T}$ allele frequencies in the MS group were significantly decreased, while the comparison of CT genotype frequency between the two groups had no significant difference. These data showed that the difference of the three genotypes and two alleles in the MS and control groups was statistically significant, showing 26.52 and 34.73 as the Chi-square test value, with a statistically significant difference.

Relationship between APN gene polymorphism and the incidence of MS. The distribution of rs121917815 genotypes and alleles in patients with MS is shown in Table III. To estimate the relationship between APN rs121917815 gene polymorphic site and the incidence of MS, the risk of MS was expressed by the odds ratio (OR). The OR of TT genotype was 0.60 ( $32 \times 78 / 37 \times 110)$, the OR of CT genotype was $0.91(42 \times 78 / 36 \times 100)$, and the OR of CC genotype was 1.64 (68x73/41x74). The OR of T allele was 0.56 (110x106/118x118), and the OR of C allele was 1.71 (178x 110/106x 108). The above results of $\mathrm{OR}$ indicated that $\mathrm{CC}$ genotype and $\mathrm{C}$ allele significantly increased the risk of MS.

Relationship of atherosclerosis-related indexes in patients with MS. The expression level changes of CRP, IL-1, HDL-2a
Table IV. Comparison of genotype AI value between the MS and control groups.

\begin{tabular}{lccc}
\hline \multirow{3}{*}{ Groups } & \multicolumn{3}{c}{ Genotypes } \\
\cline { 2 - 4 } Control & TT & CT & CC \\
\multirow{2}{*}{ MS } & $\begin{array}{c}3.79 \pm 0.34 \\
(\mathrm{n}=37)\end{array}$ & $\begin{array}{c}3.82 \pm 0.19 \\
(\mathrm{n}=36)\end{array}$ & $\begin{array}{c}4.26 \pm 0.41 \\
(\mathrm{n}=41)\end{array}$ \\
& $\begin{array}{c}3.82 \pm 0.42 \\
(\mathrm{n}=32)\end{array}$ & $\begin{array}{c}3.77 \pm 0.29 \\
(\mathrm{n}=42)\end{array}$ & $\begin{array}{c}4.36 \pm 0.14 \\
(\mathrm{n}=38)\end{array}$ \\
\hline
\end{tabular}

and HDL-2b in the blood of the control group, the metabolic abnormality group and the MS group were detected (Fig. 3), the total cholesterol and HDL of different genotypes in the three groups were detected using the MINDRAY biochemical automatic analyzer, and the AI values of the three genotypes of patients were calculated (Table IV). The study found that there was no statistical difference in the degree of atherosclerosis between the MS group and the control group as well as the metabolic abnormality group, which suggested that the rs121917815 polymorphic site was not correlated with the degree of atherosclerosis.

\section{Discussion}

Metabolic syndrome is a comprehensive disease with insulin resistance as its central link, which is manifested by central obesity, hypertension, hyperglycemia and other diseases caused by the metabolic abnormalities of glucose and lipid (12). Previous findings have shown that individuals aged more than 60 years are likely to suffer from MS, showing serious condition (13). However, data regarding the clinical description of early onset MS patients and whether MS may cause other diseases are limited. In this study, the patients with an approximate age of 55 years were selected as the main research objects to investigate the possible pathogenesis of early onset MS.

APN has been found to play an important role in blood glucose and lipid metabolism which are regulated by insulin, while it has been reported that APN multiple polymorphic sites also account for a large proportion in the pathogenesis of MS $(14,15)$. Additionally, the rs121917815 gene polymorphic site can cause T2DM, leading to severe clinical symptoms in patients (16). However, there is limited literature available regarding whether there is a relationship between this site and MS.

The origin of atherosclerosis is well known, mainly due to the metabolic abnormalities of glucose and lipid, which is similar to the pathological phenomenon caused by MS $(17,18)$. However, to the best of our knowledge, there is no report on the relationship between early onset MS and atherosclerosis. In patients with atherosclerosis, CRP and regulatory factor IL-1, which have different degrees of increase, can be used as the indexes of atherosclerosis. Additionally, combined with the calculation of atherosclerosis index, the degree of atherosclerosis in patients with MS may be evaluated by these methods (19). 
Based on the above research background, this study found that through the clinical data of patients with MS and immunoblotting for serum APN protein expression, the grouping mode and disease diagnosis were correct. In the analysis of the three groups of APN SNP rs121917815 site genotypes, we found that $\mathrm{CC}$ genotype frequency and $\mathrm{C}$ allele frequency in the MS group were significantly increased. Compared with the control group, TT genotype and T allele frequencies in the MS group were significantly decreased, while the comparison of CT genotype frequency between the two groups had no significant difference concerning the clinical description, we found that more MS symptoms appeared in this population, which indicated that $\mathrm{C}$ allele at rs121917815 was the pathogenic factor of MS. At the same time, the OR value of the three genotypes and two alleles suggested that the occurrence of CC genotype and $\mathrm{C}$ allele in rs121917815 site could increase the incidence of MS.

CRP and its regulatory factor IL-1 play an important role in the evaluation of atherosclerosis, while the serum HDL-2 $a$ and HDL-2b are also of significance in the process of atherosclerosis (20). To the best of our knowledge, for the first time, we found that there was no distinct change of CRP, IL-1, HDL-2a and HDL-2b in the patients with $\mathrm{C}$ allele in the MS group, while the difference was not statistically significant in the comparison of the AI between the MS and control groups as well as the metabolic abnormality group. There was no direct correlation between rs121917815 and atherosclerosis in cardiovascular disease.

In conclusion, APN rs121917815 gene polymorphic site is associated with the early MS and could increase the risk of MS, but the difference is not statistically significant in atherosclerosis-related indexes in MS patients with rs121917815 polymorphic site, which indicates that APN rs121917815 polymorphic site is related to MS, but it is not directly involved in the aggravation of atherosclerosis. This study has provided a theoretical basis for the pathogenesis of MS and atherosclerosis, which may be conducive to seek a particular approach for clinical treatment.

\section{Acknowledgements}

The present study was supported by the Hebei Province Science and Technology Plan (no. 15277794D).

\section{References}

1. Alberti KGM, Zimmet P and Shaw J; IDF Epidemiology Task Force Consensus Group: The metabolic syndrome - a new worldwide definition. Lancet 366: 1059-1062, 2005.

2. Gastrich MD, Lasser NL, Wien M and Bachmann G: Dietary complex carbohydrates and low glycemic index/load decrease levels of specific metabolic syndrome/cardiovascular disease risk factors. Top Clin Nutr 23: 76-96, 2008.
3. Kim B and Feldman EL: Insulin resistance as a key link for the increased risk of cognitive impairment in the metabolic syndrome. Exp Mol Med 47: e149, 2015.

4. Yamauchi T, Kamon J, Minokoshi Y, Ito Y, Waki H, Uchida S, Yamashita S, Noda M, Kita S, Ueki K, et al: Adiponectin stimulates glucose utilization and fatty-acid oxidation by activating AMP-activated protein kinase. Nat Med 8: 1288-1295, 2002.

5. Kadowaki T, Yamauchi T, Kubota N, Hara K, Ueki K and Tobe K: Adiponectin and adiponectin receptors in insulin resistance, diabetes, and the metabolic syndrome. J Clin Invest 116: 1784-1792, 2006

6. Lee $\mathrm{S}$ and Kwak HB: Role of adiponectin in metabolic and cardiovascular disease. J Exerc Rehabil 10: 54-59, 2014.

7. Nigro E, Scudiero O, Monaco ML, Palmieri A, Mazzarella G, Costagliola C, Bianco A and Daniele A: New insight into adiponectin role in obesity and obesity-related diseases. Biomed Res Int 2014: 658913, 2014. https://doi.org/10.1155/2014/658913.

8. Fu Y: Adiponectin signaling and metabolic syndrome. Prog Mol Biol Transl Sci 121: 293-319, 2014.

9. Bouatia-Naji N, Meyre D, Lobbens S, Séron K, Fumeron F, Balkau B, Heude B, Jouret B, Scherer PE, Dina C, et al: ACDC/adiponectin polymorphisms are associated with severe childhood and adult obesity. Diabetes 55: 545-550, 2006.

10. Al-Daghri NM, Al-Attas OS, Alokail MS, Alkharfy KM, Hussain T, Yakout S, Vinodson B and Sabico S: Adiponectin gene polymorphisms (T45G and G276T), adiponectin levels and risk for metabolic diseases in an Arab population. Gene 493: 142-147, 2012.

11. Cai X, Gan Y, Fan Y, Hu J, Jin Y, Chen F, Chen T, Sun Y, Wang J, Qin W, et al: The adiponectin gene single-nucleotide polymorphism rs1501299 is associated with hepatocellular carcinoma risk. Clin Transl Oncol 16: 166-172, 2014.

12. Samson SL and Garber AJ: Metabolic syndrome. Endocrinol Metab Clin North Am 43: 1-23, 2014.

13. Yesil A and Yilmaz Y: Review article: Coffee consumption, the metabolic syndrome and non-alcoholic fatty liver disease. Aliment Pharmacol Ther 38: 1038-1044, 2013.

14. Stumvoll M, Tschritter O, Fritsche A, Staiger H, Renn W, Weisser M, Machicao F and Häring H: Association of the T-G polymorphism in adiponectin (exon 2) with obesity and insulin sensitivity: Interaction with family history of type 2 diabetes. Diabetes 51: 37-41, 2002.

15. Fredriksson J, Carlsson E, Orho-Melander M, Groop L and Ridderstråle M: A polymorphism in the adiponectin gene influences adiponectin expression levels in visceral fat in obese subjects. Int J Obes 30: 226-232, 2006.

16. Zietz B, Buechler C, Kobuch K, Neumeier M, Schölmerich J and Schäffler A: Serum levels of adiponectin are associated with diabetic retinopathy and with adiponectin gene mutations in Caucasian patients with diabetes mellitus type 2. Exp Clin Endocrinol Diabetes 116: 532-536, 2008.

17. Hutter N, Baena M, Sangüesa G, Dávalos A, Latasa MJ, Escolà-Gil JC, Sánchez RM, Roglans N, Alegret M and Laguna JC: Liquid fructose supplementation in LDL- $\mathrm{R}^{-/}$mice fed a western-type diet enhances lipid burden and atherosclerosis despite identical calorie consumption. Int J Cardiol 9: 12-21, 2015.

18. Shih DM, Wang Z, Lee R, Meng Y, Che N, Charugundla S, Qi H, Wu J, Pan C, Brown JM, et al: Flavin containing monooxygenase 3 exerts broad effects on glucose and lipid metabolism and atherosclerosis. J Lipid Res 56: 22-37, 2015.

19. Rudolf J and Lewandrowski KB: Cholesterol, lipoproteins, high-sensitivity c-reactive protein, and other risk factors for atherosclerosis. Clin Lab Med 34: 113-127, vii, 2014.

20. Parhofer KG: Increasing HDL-cholesterol and prevention of atherosclerosis: A critical perspective. Atheroscler Suppl 18: 109-111, 2015. 